\title{
Comparison of Two- and Three-dimensional Ultrasonography in the Evaluation of Lesion Level in Fetuses with Spina Bifida
}

\section{Comparação entre a ultrassonografia bidimensional e a ultrassonografia tridimensional na avaliação do nível da lesão nos fetos com espinha bífida}

\author{
Márcio José Rosa Requeijo ${ }^{1,2}$ Victor Bunduki ${ }^{2}$ Rossana Pulcineli Vieira Francisco ${ }^{2}$ \\ Marco Antonio Borges Lopes ${ }^{2}$ Rodrigo Ruano ${ }^{2}$ Marcelo Zugaib ${ }^{2}$ \\ ${ }^{1}$ Departamento de Obstetrícia e Ginecologia, Faculdade de Medicina \\ de Itajubá, Itajubá, MG, Brazil \\ 2 Departamento de Obstetrícia e Ginecologia, Faculdade de Medicina, \\ Universidade de São Paulo, São Paulo, SP, Brazil \\ Address for correspondence Márcio José Rosa Requeijo, MD, PhD, \\ Faculdade de Medicina, Universidade de São Paulo, Av. Dr. Enéas de \\ Carvalho Aguiar, 255, $10^{\circ}$ andar, Cerqueira César, São Paulo, SP, Brasil \\ 05403-010 (e-mail: marciorequeijo3@hotmail.com).
}

Rev Bras Ginecol Obstet 2016;38:120-126.
Abstract
Keywords
- fetus
- two-dimensional ultrasonography
- three-dimensional ultrasonography
- spina bifida

Purpose To evaluate the precision of both two- and three-dimensional ultrasonography in determining vertebral lesion level (the first open vertebra) in patients with spina bifida.

Methods This was a prospective longitudinal study comprising of fetuses with open spina bifida who were treated in the fetal medicine division of the department of obstetrics of Hospital das Clínicas of the Universidade de São Paulo between 2004 and 2013. Vertebral lesion level was established by using both two- and three-dimensional ultrasonography in 50 fetuses (two examiners in each method). The lesion level in the neonatal period was established by radiological assessment of the spine. All pregnancies were followed in our hospital prenatally, and delivery was scheduled to allow immediate postnatal surgical correction.

Results Two-dimensional sonography precisely estimated the spina bifida level in 53\% of the cases. The estimate error was within one vertebra in $80 \%$ of the cases, in up to two vertebrae in $89 \%$, and in up to three vertebrae in $100 \%$, showing a good interobserver agreement. Three-dimensional ultrasonography precisely estimated the lesion level in $50 \%$ of the cases. The estimate error was within one vertebra in $82 \%$ of the cases, in up to two vertebrae in $90 \%$, and in up to three vertebrae in $100 \%$, also showing good interobserver agreement. Whenever an estimate error was observed, both two- and three-dimensional ultrasonography scans tended to underestimate the true lesion level ( $55.3 \%$ and $62 \%$ of the cases, respectively).

Conclusions No relevant difference in diagnostic performance was observed between the two- and three-dimensional ultrasonography. The use of three-dimensional received

October 13, 2015

accepted

January 6, 2016

published online

March 21, 2016
DOI http://dx.doi.org/

$10.1055 / \mathrm{s}-0036-1580711$ ISSN $0100-7203$.
Copyright $\odot 2016$ by Thieme Publicações License terms

Ltda, Rio de Janeiro, Brazil
$\Theta(1) \Theta \circledast$ 
ultrasonography showed no additional benefit in diagnosing the lesion level in the fetuses with spina bifida. Errors in both methods showed a tendency to underestimate lesion level.

\section{Resumo}

\author{
Palavras-chave \\ - fetos \\ - ultrassom \\ bidimensional \\ - ultrassom \\ tridimensional \\ - espinha bífida
}

Objetivo Avaliar a precisão da ultrassonografia bidimensional e tridimensional para a determinação do nível da lesão vertebral em casos de fetos portadores de espinha bífida.

Métodos Estudo prospectivo longitudinal, compreendendo fetos portadores de espinha bífida assistidos no setor de medicina fetal de hospital de ensino do Sudeste do Brasil, entre os anos de 2004 e 2013. Foram incluídos 50 fetos portadores de espinha bífida pela ultrassonografia bidimensional e tridimensional (dois examinadores em cada método) com relação ao nível da lesão. O nível exato da lesão foi verificado usando radiografia após o nascimento.

Resultados A ultrassonografia bidimensional estimou corretamente o nível de espinha bífida em $53,0 \%$ dos casos. Em $80,0 \%$ dos casos a estimativa ocorreu com erro de uma vértebra; $89,0 \%$ em até duas vértebras e de $100,0 \%$ em até três vértebras. A ultrassonografia tridimensional estimou corretamente o nível de espinha bífida em $50,0 \%$ dos casos. Em 82,0\% dos casos, a estimativa ocorreu com erro de uma vértebra; $90,0 \%$ em até duas vértebras e de 100,0\% em até três vértebras. Nos casos em que houve erro na estimativa do nível da lesão, tanto na avaliação bidimensional quanto na tridimensional, observou-se tendência a subestimar o nível da lesão vertebral $(55,3 \%$ na avaliação bidimensional e $62,0 \%$ na tridimensional), ou seja, colocando o nível ultrassonográfico mais baixo que o observado no pós-natal.

Conclusões Não houve diferenças relevantes entre o desempenho diagnóstico da ultrassonografia bidimensional e tridimensional para determinação do nível da lesão vertebral nos casos de fetos portadores de espinha bífida. Tendência a subestimação do nível de lesão nos casos em que houve erro tanto na ultrassonografia bidimensional quanto na tridimensional.

\section{Introduction}

Spina bifida is characterized by an incomplete formation of the structures that protect the spinal cord through inappropriate closing of the backbone, which may present as open and hidden forms, with or without neurological involvement. The most common types are myelomeningocele and meningocele, which are open forms of spina bifida and may result in severe neurological sequels, with an incidence of 0.5 to 0.8 per thousand live births. ${ }^{1}$

This defect occurs as a result of genetic and environmental factors. Many causes have been proposed, such as folate deficiency, maternal diabetes, zinc deficiency, ingestion of alcohol during the first 3 months of pregnancy, and maternal exposure to certain drugs such as carbamazepine and valproic acid. ${ }^{2}$ Spina bifida can be prevented by supplementation of folic acid in the periconceptional period, starting 3 months before conception and up to the third month of pregnancy. 3,4

Correction of this defect may be performed during the intrauterine or postnatal period. ${ }^{5-7}$ The MOMS study (Management of Myelomeningocele Study) showed that prenatal fetal surgery for myelomeningocele decreased the need of placing a ventriculoperitoneal shunt, and improved cognitive and motor development within 30 months of life. One of the selection criteria in this study was fetuses with open spina bifida between $\mathrm{T} 1$ and S1. Therefore, the correct diagnosis of lesion level is an important factor for surgical indication..$^{8-11}$ With regard to the diagnosis of spina bifida in the gestational period, ultrasonography is the method of choice, as it is able to detect around $80 \%$ to $100 \%$ of cases. ${ }^{12}$

In the first quarter, the assessment of intracranial translucency between the 11th and 14th weeks is a promising technique. In fetuses with spina bifida, the disappearance of the fourth ventricle is observed in the caudal displacement of the hindbrain. ${ }^{13,14}$ In the second and third quarters, both two- and three-dimensional ultrasonography are useful for directly observing the vertebral lesion. The definition of the lesion level is considered as the determining factor of fetal prognosis and the prediction of possible secondary complications, which entail counseling of the pregnant woman, her family, and the professionals involved. Bruner et al, ${ }^{15}$ however, stated that the method presents some limitations as to the correct diagnosis of the lesion level, demonstrating that two-dimensional ultrasonography defines exactly the 
postdelivery levels of the vertebral lesion in only $38 \%$ of the cases, increasing this setting to $96 \%$ within two levels and reaching $100 \%$ within three levels, that is, when performed in reference centers by trained professionals. The observation of the possibility of errors up to three levels undermines its use as a decisive factor in the management of this malformation because errors of that magnitude result in widely varied injury prognosis regarding ambulation and motor strength, mainly of the lower limbs, in addition to control of vesical and anal sphincters.

Three-dimensional ultrasonography has been described as an important adjuvant method for assessing numerous fetal malformations, but its superiority to two-dimensional ultrasonography with regard to the diagnosis of the injury level in fetuses with spina bifida is controversial. ${ }^{16-20}$ The absence of conclusive data in relation to the comparison between two- and three-dimensional ultrasonography in the evaluation of injury level in cases of spina bifida motivated us to conduct this study.

\section{Methods}

A prospective longitudinal study was conducted with the objective of evaluating fetuses with isolated spina bifida and without chromosomopathies who were treated in the fetal medicine division of the department of obstetrics and gynecology of Hospital das Clínicas of the Universidade de São Paulo (HC-FM-USP) between October 2004 and March 2013. This study was approved by the ethics committee for the analysis of research projects of the HC-FM-USP. The authors did not receive financial support, equipment, or medicines from any other institution and had no conflicts of interest. The inclusion and exclusion criteria in this study were as follows: diagnosis of isolated open spina bifida on fetal morphologic ultrasonography; had been evaluated twice on two-dimensional ultrasonography, with assessment of lesion level, by two examiners in charge on the same day, using the same technique; two three-dimensional ultrasonography evaluations, with evaluation of lesion level, by two examiners in charge on the same day, using the same technique; and confirmed injury level in spina bifida by using simple postnatal radiography. The exclusion criterion was birth in another service.

From October 2004 to March 2013, in the fetal medicine division of HC-FM-USP, 270 fetuses were diagnosed with spina bifida. Among these fetuses, 220 did not meet the inclusion criteria and thus were excluded (122 cases due to associated malformations and 98 cases for not having been postnatally evaluated). Finally, we included 50 fetuses who were considered as fit to participate in this study.

With regard to the calculation of the sample size, our hypothesis was that $50 \%$ concordance would be found between the two methods, ranging from $35 \%$ and $65 \%$. To obtain estimates with $95 \%$ confidence intervals, we needed to include at least 43 cases in the study. As the eligible number of fetuses with spina bifida was 50 , the sample size was considered satisfactory. ${ }^{21}$
The pregnant women whose fetuses were diagnosis with spina bifida were interviewed by the researchers. If they agreed to participate in the study, they were asked to sign an informed consent form. These patients were forwarded to the prenatal fetal medicine group and followed up to term. As support, the pregnant women were referred to the department of psychology of the obstetric clinic of the same institution, with the first consultation preferably after ultrasonography diagnosis. The parturition was programed in the service jointly with the neurosurgery department.

The information was entered in the registration database of patients through a specific software (Microsoft Access 2007), including the examination date, overall record, address, contact number, name, mother's age in years, parity, personal and family histories of spina bifida, gestational age at diagnosis (date of last menstruation compatible with the obstetric ultrasonography performed until the 12 th week, or at least two ultrasonography examinations concordant up to the 20th week).

In relation to the specific data that correlated with the location of the spina bifida, each fetus was evaluated by the two examiners responsible for each technique. Thus, the total number of two- and three-dimensional evaluations in the study was 100 each.

After birth, radiography was performed to assess lesion level (considered the gold standard for its location). ${ }^{16}$ The injury levels obtained by using two- and three-dimensional ultrasonography were compared with the postnatal radiological levels and classified as coincidental in relation to the findings. That is, the lesion level in the spine on simple radiography coincided with the level found on ultrasonography. Errors were classified as follows: error at one level, the lesion level ranged from less to more than one vertebra; error at two levels, the level of lesion ranged from less to more than two vertebrae; and error at three levels, the lesion level ranged from less to more than three vertebrae.

Data were analyzed by using the Statistical Package for Social Sciences (SPSS) version 20 (IBM SPSS statistics). The categorical variables were expressed as means, medians, and standard deviations, and absolute and relative frequencies. The Fisher exact test was used for comparison of proportions.

For the two-dimensional ultrasonography assessment, median sagittal, coronal, and transverse sections of the spine were obtained. ${ }^{15}$ The lesion level was obtained by counting the vertebrae craniocaudally, starting from the cervical vertebrae up to the first abnormal opening of the side plates. That is, the vertebra was more affected cranially by the closure defect. In addition, the last ribs were used as reference points, coinciding with the 12th thoracic vertebra and the iliac crest as the level of the fifth lumbar vertebra ${ }^{15,22}$ (-Fig. 1).

The first observer performed the evaluation, noting the level of the lesion. On the same day, the second observer also performed examinations by using the same technique, without knowledge of the results obtained by the previous operator. The device used was the GE Voluson 730 Expert ultrasound system (Austria). 


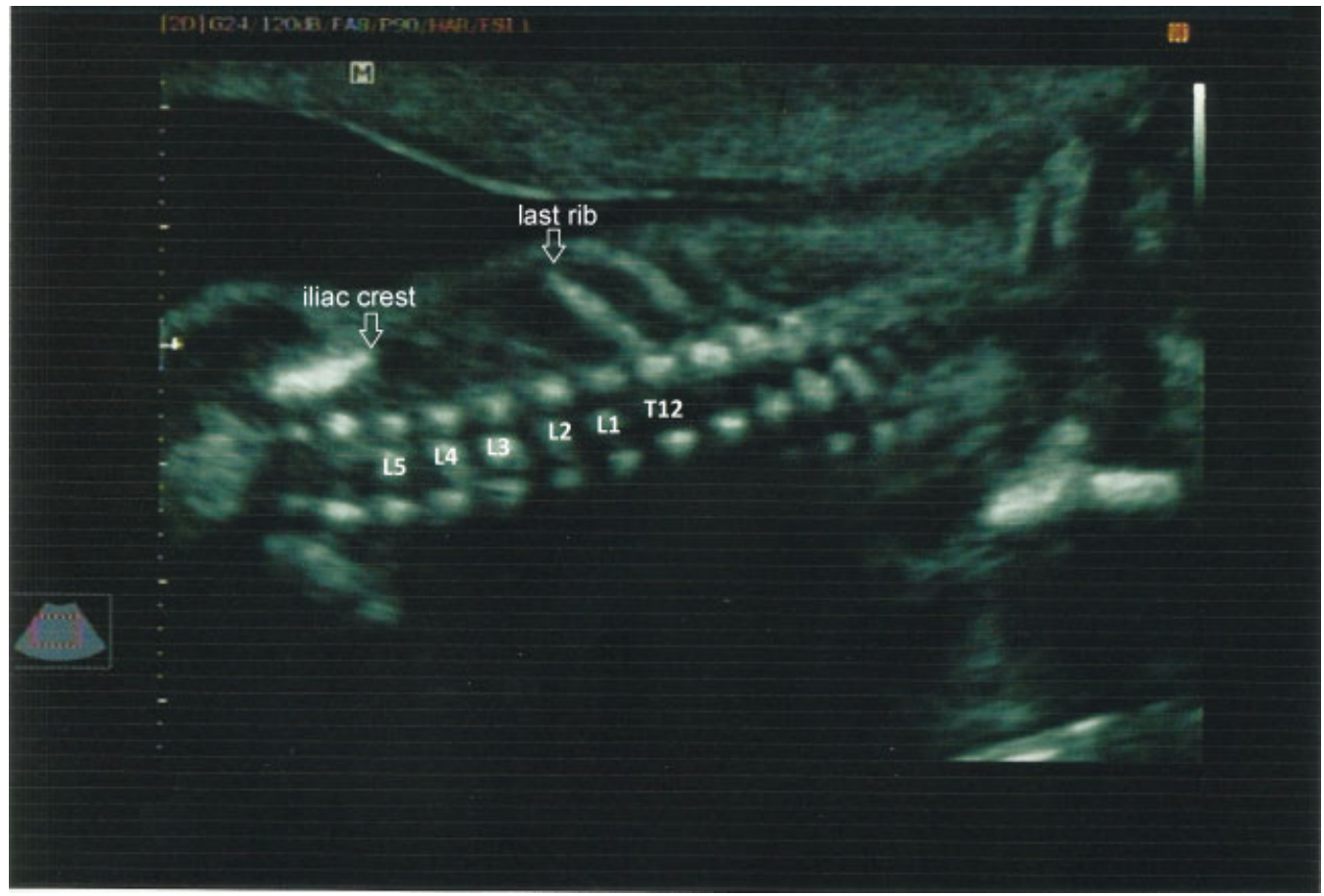

Fig. 1 Two-dimensional evaluation showing points of reference for assessing the injury level in the cases of spina bifida, in which the last rib is considered as the level of the 12th thoracic vertebra (T12) and the iliac crest is considered as the level of the fifth lumbar vertebra (L5).

The three-dimensional ultrasonography assessment was performed from a sagittal section of the fetal spine. The volumetric window was adjusted to capture the whole region of the vertebral column. In fetuses with more advanced gestational ages, two or more partial acquisitions of the spine were performed, which allowed the observation of spina bifida. The sweep angle was adjusted to capture only the vertebral column $\left(15^{\circ}\right.$ to $\left.30^{\circ}\right)$, selecting the high-resolution skeletal mode ${ }^{18,20}$ (- Fig. 2).

The lesion level was determined by counting the vertebrae craniocaudally, starting from the cervical vertebrae up to the first abnormal opening of the side plates. That is, the vertebra was more cranially affected by the closing defect. In addition, the last ribs were used as reference points, coinciding with the 12th thoracic vertebra and the iliac crest as the level of the fifth lumbar vertebra. ${ }^{15,22}$

The first observer performed the evaluation, noting the level of the lesion. On the same day, the second observer also performed examinations by using the same technique, without knowledge of the results obtained by the previous operator. The device used was the GE Voluson 730 Expert ultrasound system (Austria).

\section{Characterization of the Studied Population}

The mean maternal age in this study was 26.8 years, with a standard deviation of 7.2 years and a median of 24.1 years (range, 16.2-45.1 years). By dividing according to age group, we found an incidence of $18 \%, 20 \%$, and $62 \%$ in mothers aged $\leq 19$ years, $>35$ years, and 20 to 34 years, respectively.

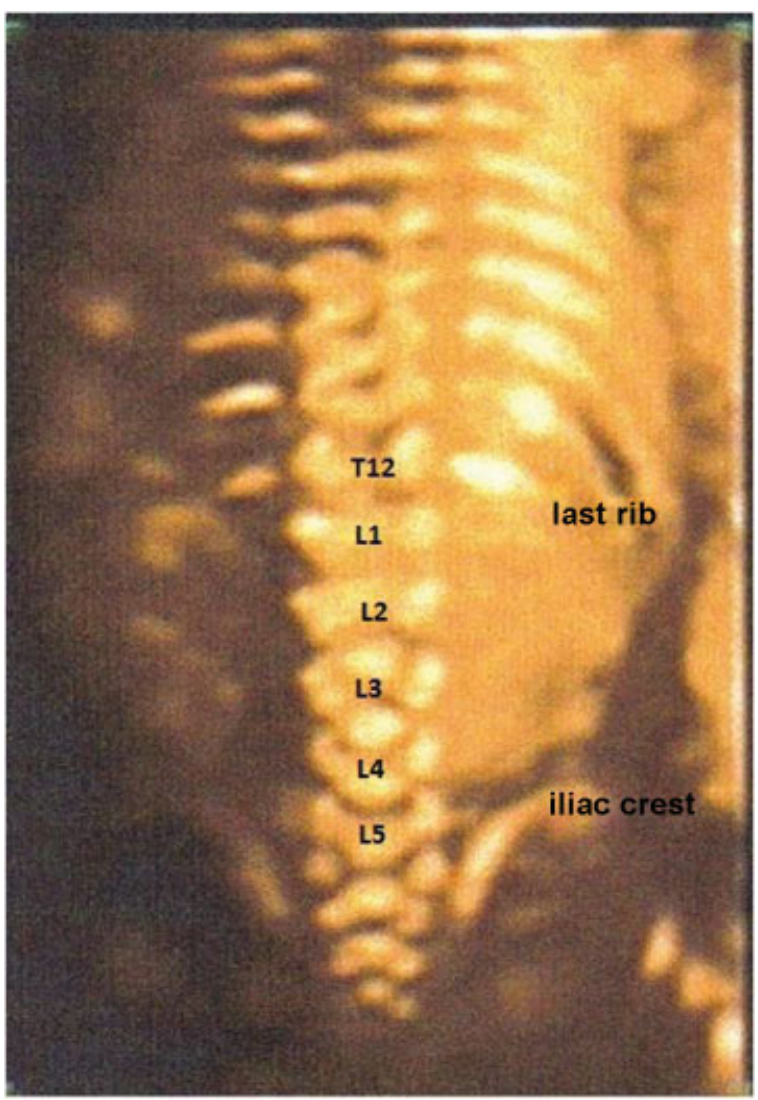

Fig. 2 Three-dimensional evaluation showing points of reference for assessing lesion level in the cases of spina bifida in which the last rib is considered as the level of the 12 th thoracic vertebra (T12) and the iliac crest is considered as the level of the fifth lumbar vertebra (L5). 
124 Comparison of 2D and 3D Ultrasound of Lesion Level in Fetuses with Spina Bifida Requeijo et al.

Table 1 Characterization of the study population

\begin{tabular}{|l|l|l|l|}
\hline Variables & & $\mathbf{n}$ & $\%$ \\
\hline MA & Up to 19 years & 9 & 18.0 \\
\hline & From 20 to 34 years & 31 & 62.0 \\
\hline & Older than 35 years & 10 & 20.0 \\
\hline & Mean (SD): 26.8 (7.2) years & & \\
& Median: 24.1 years & & \\
\hline Pregnancies & G1 & 34 & 68.0 \\
\hline & G2 & 9 & 18.0 \\
\hline & G3 & 2 & 4,0 \\
\hline & G4 or above & 5 & 10.0 \\
\hline GA & $1 T$ & 0 & 0.0 \\
\hline & $2 T$ & 24 & 48.0 \\
\hline & $3 T$ & 26 & 52.0 \\
\hline & Mean (SD): 28 (5.2) weeks & & \\
\hline FH & Median: 27.1 weeks & & \\
\hline & Yes & 0 & 0.0 \\
\hline Location & No & 50 & 100.0 \\
\hline & Cervical & 3 & 6.0 \\
\hline & Thoracic & 7 & 14,0 \\
\hline & Lumbar & 39 & 78.0 \\
\hline & Sacral & 1 & 2.0 \\
\hline
\end{tabular}

Abbreviations: FH, family history; GA, gestational age at diagnosis; MA, maternal age.

With regard to the number of gestations, primigravidae accounted for the highest incidence in this study, with 34 cases $(68.0 \%)$, followed by second pregnancies, with 9 (18.0\%); third pregnancies, with 2 (4.0\%); and other parities (up to the sixth pregnancy), with 5 (10.0\%). The mean (SD) gestational age when the first ultrasonography was performed in our institution was 28.0 (5.2) weeks, with a median of 27.1 weeks (range, 18-38 weeks). Of the cases, none was diagnosed in the first quarter, $48.0 \%$ (24 cases) were diagnosed in the second quarter, and 52\% (26 cases) were diagnosed in the third quarter. No personal or family history of spina bifida was found in the studied population (-Table 1). The locations of the lesions in the fetuses affected were distributed as follows: cervical vertebrae, 3 cases
(6.0\%); thorax, 7 cases (14.0\%); lumbar spine, 39 cases (78.0\%); and sacral vertebra, 1 case $(2.0 \%)$.

\section{Results}

Regarding the results in the two-dimensional ultrasonography group, with a total of 100 evaluations, the level of coincidence obtained was $53 \%$ of the cases. With an error at one, two, and 3 levels, this coincidence level increased to $80 \%, 89 \%$, and $100 \%$, respectively (-Table 2 ).

As to the results of the three-dimensional ultrasonography group, with a total of 100 evaluations, the level of coincidence obtained was $50 \%$ of the cases. This increased to $82 \%$ with an error at one level, to $90 \%$ with an error at two

Table 2 Evaluation of the combined results of the observers who performed USG-2D and USG-3D in relation to coincidence and levels of error

\begin{tabular}{|l|l|l|l|l|l|}
\hline & $\begin{array}{l}\text { Coincidences } \\
\mathbf{n}(\%)\end{array}$ & $\begin{array}{l}\mathbf{1} \text { Level } \\
\mathbf{n}(\%)\end{array}$ & $\begin{array}{l}\mathbf{2} \text { Levels } \\
\mathbf{n}(\%)\end{array}$ & $\begin{array}{l}\text { 3 Levels } \\
\mathbf{n}(\%)\end{array}$ & $\begin{array}{l}\text { Total } \\
\text { Evaluations }\end{array}$ \\
\hline USG-2 D & $53(53)$ & $\begin{array}{l}27(27) \\
\text { Cumulative: } \\
80 \%\end{array}$ & $\begin{array}{l}9(9) \\
\text { Cumulative: } \\
89 \%\end{array}$ & $\begin{array}{l}11(11) \\
\text { Cumulative: } \\
100 \%\end{array}$ \\
\hline USG-3D & $50(50)$ & $\begin{array}{l}32(32) \\
\text { Cumulative: } \\
82,0 \%\end{array}$ & $\begin{array}{l}8(8) \\
\text { Cumulative: } \\
90 \%\end{array}$ & $\begin{array}{l}10(10) \\
\text { Cumulative: } \\
100 \%\end{array}$ \\
\hline
\end{tabular}

Abbreviations: USG-2D: two-dimensional ultrasound; USG-3D: three-dimensional ultrasound. 
levels, and to $100 \%$ with an error at up to three levels. No significant difference was observed between the two-and three-dimensional ultrasonography methodology in the Fisher exact test (with a level of significance of 0.05).

In the cases in which an error occurred at one lesion level in the two-dimensional ultrasonography group, the lesion level tended to be underestimated in $55.3 \%$ of the assessments and overestimated at the injury level in $44.7 \%$ of the cases. In the three-dimensional ultrasonography group, the injury level tended to be underestimated in $62 \%$ of the assessments and overestimated in $38 \%$ of the cases.

\section{Discussion}

Neural tube defects cause high incidence rates of perinatal and infant mortality, and severe chronic complications in survivors. In the case of spina bifida, prenatal diagnosis enables better understanding of the problem and the associated conditions that help, among other actions, in the planning of birth and interventions that may be necessary.

Individuals with spina bifida may present motor and sensory loss mainly in the lower extremities, urological complications, neurogenic bowel dysfunction, orthopedic complications, pressure ulcers, cognitive deficiency, and allergies, with varying degrees of disability and dependence for prostheses, crutches, wheelchair, or third-party aid throughout life. The severity of these complications, the point of neurological dysfunction, and the presence of associated complications, though imperfectly, may be predicted based on the lesion level in these patients. The higher the injury level, the more serious the complications. ${ }^{23}$

With regard to ultrasonography diagnosis in cases of spina bifida, the accuracy of determining the lesion level by using two-dimensional ultrasonography widely varied, with values ranging from $38 \%$ to $64 \%$. This variation can reach up to three vertebral levels. ${ }^{15,22}$

With respect to the accuracy of three-dimensional ultrasonography in determining lesion level, Cameron and Moran ${ }^{17}$ demonstrated that three-dimensional ultrasonography can reach diagnostic accuracy within one vertebral body in $\sim 80 \%$ of the patients. Buyukkurt et al ${ }^{16}$ demonstrated a $79.0 \%$ level of accuracy, reaching $100 \%$ with a margin of one level.

With regard to the ultrasonography location of the lesion, our results demonstrated an accuracy of 53\% for the twodimensional ultrasonography assessment and $50.0 \%$ for the three-dimensional ultrasonography assessment. However, if we considered an error at one vertebral level, this index reached $80 \%$ and $82.0 \%$ in two- and three-dimensional ultrasonography, respectively, which are values similar to those obtained by other authors. ${ }^{15}$ However, we only reached $100 \%$ concordance, considering an error margin of three vertebral levels both in two- and three-dimensional ultrasonography.

In relation to the error in the diagnosis of the vertebral level, we observed a tendency to underestimate lesion levels. That is, we observed a tendency to place the lesion level to lower than that observed after birth, both in the two- and three-dimensional methodology (55.3\% and $62.0 \%$, respectively), compared with the error by overestimation of the injury level (44.7\% and 38.0\%, respectively). With this observation, we conclude that in case of doubt on the vertebral lesion level, we should opt for the highest lesion level to have a higher chance of concordance.

We conclude that inadequate evaluation of the anatomical reference points for the assessment of the vertebrae involved seems to be a factor that can affect results. In the evaluation of the last rib, as a point of reference for the $12^{\text {th }}$ thoracic vertebra (T12), owing to its small size, it may not be visible in cases of excessive angulation of the spine, leading to error. Excessive angulation of the spine can also make the assessment difficult and lead to error when using the iliac crest with reference to the fifth lumbar vertebra (L5). Therefore, the spine must be rectified if possible for the use of these points of reference.

In fetuses with gestational ages close to 20 weeks, ossification in the topography of the fifth sacral vertebra could not be observed. Whereas in fetuses in the third quarter, this assessment was possible. Taking into account this finding, the vertebrae counted toward the caudocranial direction in the second quarter could demonstrate a lower vertebral level than the actual level, which could lead to an underestimation of the lesion level. A similar finding was reported by Kollias et al. ${ }^{22}$ Therefore, the ideal technique for the evaluation of the spine should position it as rectified as possible, and the direct counting of the vertebrae should always be performed in the craniocaudal direction. Knowledge of these facts allows for more accurate diagnosis of lesion level and should not be disregarded.

Few studies have compared the accuracies of two- and three-dimensional ultrasonography for the diagnosis of spina bifida. These studies claim that three-dimensional ultrasonography is a complementing methodology and does not replace two-dimensional ultrasonography. ${ }^{18,19}$ Our findings are concordant with these studies. No significant differences were observed between these methodologies. Thus, based on our results, we conclude that the use of three-dimensional ultrasonography had no advantages to two-dimensional ultrasonography for the diagnosis of the location of the injury level in spina bifida.

The data obtained in this study demonstrate that even in the best conditions, with modern ultrasound apparatus and highly qualified personnel, the identification of lesion level is far from perfect. Although our operators have extensive experience in ultrasonography for fetal malformations, especially in fetuses with spina bifida, the precision level of both two- and three-dimensional ultrasonography was lower, by nearly $50.0 \%$, than that of postnatal radiological evaluation. This causes concern regarding the use of ultrasonography as a defining factor of injury level in cases of spina bifida. Finally, we emphasize that our study indicates the need for continuous improvement of medical sonographers who wish to study fetuses with spina bifida and to correctly diagnose lesion level because this assessment is technically difficult owing to countless variables present and correct diagnosis is important. 


\section{References}

1 American College of Obstetricians and Gynecologists. ACOG technical bulletin no. 99: prenatal detection of neural tube defects. Washington (DC): ACOG; 1986

2 Wegner C, Nau H. Alteration of embryonic folate metabolism by valproic acid during organogenesis: implications for mechanism of teratogenesis. Neurology 1992;42(4, Suppl 5): $17-24$

3 McDonnell R, Johnson Z, Doyle A, Sayers G. Determinants of folic acid knowledge and use among antenatal women. J Public Health Med 1999;21(2):145-149

4 Wald NJ, Law MR, Morris JK, Wald DS. Quantifying the effect of folic acid. Lancet 2001;358(9298):2069-2073

5 Bruner JP, Tulipan N, Paschall RL, et al. Fetal surgery for myelomeningocele and the incidence of shunt-dependent hydrocephalus. JAMA 1999;282(19):1819-1825

6 Hirose S, Farmer DL, Albanese CT. Fetal surgery for myelomeningocele. Curr Opin Obstet Gynecol 2001;13(2):215-222

7 Bruner JP, Tulipan NE, Richards WO. Endoscopic coverage of fetal open myelomeningocele in utero. Am J Obstet Gynecol 1997;176 (1 Pt 1):256-257

8 Adzick NS, Thom EA, Spong CY, et al; MOMS Investigators. A randomized trial of prenatal versus postnatal repair of myelomeningocele. N Engl J Med 2011;364(11):993-1004

9 Meuli M, Moehrlen U. Fetal surgery for myelomeningocele is effective: a critical look at the whys. Pediatr Surg Int 2014; 30(7):689-697

10 Flake A. Percutaneous minimal-access fetoscopic surgery for myelomeningocele - not so minimal!. Ultrasound Obstet Gynecol 2014;44(5):499-500

11 Adzick NS. Fetal surgery for spina bifida: past, present, future. Semin Pediatr Surg 2013;22(1):10-17

12 Okumura M, Zugaib M. Ultra-Sonografia em obstetrícia. São Paulo: Sarvier; 2002
13 Orlandi E, Rossi C, Perino A, Cucinella G, Orlandi F. Prospective sonographic detection of spina bifida at 11-14 weeks and systematic literature review. J Matern Fetal Neonatal Med 2015:1-5 [Epub ahead of print]

14 Chaoui R, Benoit B, Mitkowska-Wozniak H, Heling KS, Nicolaides $\mathrm{KH}$. Assessment of intracranial translucency (IT) in the detection of spina bifida at the 11-13-week scan. Ultrasound Obstet Gynecol 2009;34(3):249-252

15 Bruner JP, Tulipan N, Dabrowiak ME, et al. Upper level of the spina bifida defect: how good are we? Ultrasound Obstet Gynecol 2004; 24(6):612-617

16 Buyukkurt S, Binokay F, Seydaoglu G, et al. Prenatal determination of the upper lesion level of spina bifida with three-dimensional ultrasound. Fetal Diagn Ther 2013;33(1):36-40

17 Cameron M, Moran P. Prenatal screening and diagnosis of neural tube defects. Prenat Diagn 2009;29(4):402-411

18 Lee W, Chaiworapongsa T, Romero R, et al. A diagnostic approach for the evaluation of spina bifida by three-dimensional ultrasonography. J Ultrasound Med 2002;21(6):619-626

19 Carletti A, Ghi T, Ceccarini M, et al. OC160: three-dimensional ultrasonography is of limited value in diagnosing fetal spina bifida. Ultrasound Obstet Gynecol 2007;30(4):416

20 Wei Q, Cai A, Wang X, Xie L, Wang B, Wang X. Value of 3-dimensional sonography for prenatal diagnosis of vertebral formation failure. J Ultrasound Med 2013;32(4):595-607

21 Rosner BA. Fundamentals of biostatistics. 4th ed. Belmont: Duxbury Press; 1995

22 Kollias SS, Goldstein RB, Cogen PH, Filly RA. Prenatally detected myelomeningoceles: sonographic accuracy in estimation of the spinal level. Radiology 1992;185(1):109-112

23 Verbeek RJ, van der Hoeven JH, Maurits NM, Brouwer OF, Hoving EW, Sival DA. In spina bifida aperta, muscle ultrasound can quantify the "second hit of damage". Childs Nerv Syst 2013; 29(3):469-474 